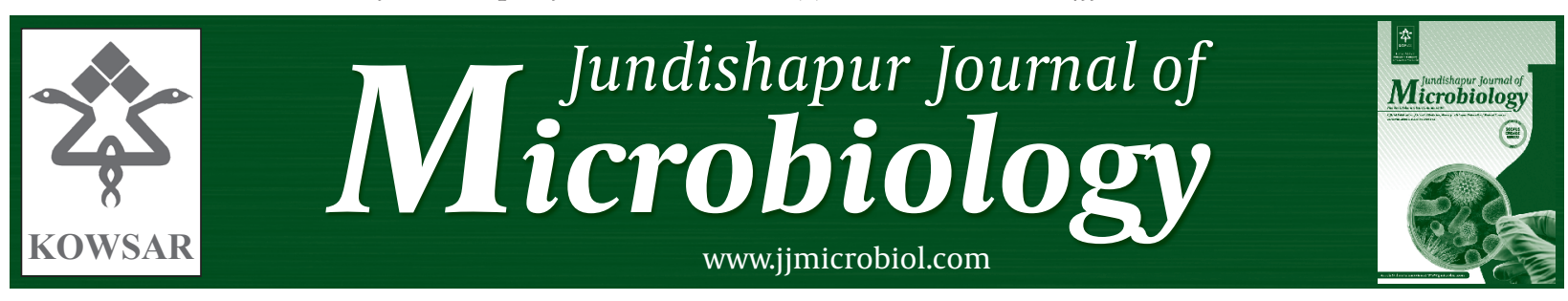

\title{
Antifungal Susceptibility of Candida Species Isolated From Candiduria
}

\author{
Ali Zarei Mahmoudabadi ${ }^{1,2}$, Majid Zarrin ${ }^{1 *}$, Maryam Beheshti Fard ${ }^{1}$ \\ ${ }^{1}$ Department of Medical Mycology, School of Medicine, Ahvaz Jundishapur University of Medical Sciences, Ahvaz, IR Iran \\ ${ }^{2}$ Infectious Diseases and Tropical Medicine Centre, Ahvaz Jundishapur University of Medical Sciences, Ahvaz, IR Iran
}

\begin{tabular}{l}
\hline A R T I C L E I N F O \\
\hline Article type: \\
Original Article \\
\hline Article history: \\
Received: 28 Feb 2012 \\
Revised: 15 Apr 2012 \\
Accepted: 28 Apr 2012 \\
\hline
\end{tabular}

Keywords:

Antifungal Agents

Susceptibility

Candiduria

Candida Species

\begin{abstract}
A B S T R A C T
Background: Candiduria is one of the most common symptoms of urinary tract infections caused by several species of Candida spp.. Several antifungals are available to treat such candidal infections. During the last decades, resistance to antifungal especially to non-albicans species has increased.

Objectives: The present study aimed to evaluate the susceptibility to antifungal drugs of Candida species isolated from candiduria in Ahvaz.

Materials and Methods: Ninety three species of yeasts and yeast like organisms isolated from urine samples [Candida albicans (58), C. glabrata (25), C. tropicalis (4), C. krusei (1), unknown Candida species (4) and Geotrichum species (1)] were used for susceptibility tests. All species were re-identified based on standard mycological methods. Then a suspension of each isolate of overnight cultures was prepared in $1 \mathrm{ml}$ of sterile PBS and adjusted to 0.5 McFarland turbidity standards. In the present study several antifungal drugs (fluconazole, amphotericine B, ketoconazole, econazole, itraconazole) were used for susceptibility test using disk diffusion method.

Results: In the present study all tested isolates were sensitive/dose dependent to amphotericine B and nystatin, whereas only one isolate of C. glabrata was resistant to both antifungals. Resistance against fluconazole (48.4\%) and ketoconazole (26.9\%) were observed among tested isolates. Resistance against fluconazole was detected among all tested organisms, $34.4 \%$ of C. albicans, and $7.5 \%$ of C. glabrata. On the other hand, all isolates were sensitive to econazole ( $93.5 \%$ sensitive, $6.5 \%$ dose dependent).

Conclusions: It was concluded that Candida species isolated from candiduria in hospitalized patients had excellent in vitro sensitivity against econazole. Other suitable antifungal drugs were amphotericine B and nystatin, itraconazole. Whereas, resistance against ketoconazole (26.9\%) and especially fluconazole (48.4\%) was significant.
\end{abstract}

Published by Kowsar Corp, 2013. cc 3.0.

Implication for health policy/practice/research/medical education:

Candiduria is a common infection of the urinary tract. Evaluation of the susceptibility to antifungal drugs could be used for treatment and control of infection.

- Please cite this paper as:

Zarei Mahmoudabadi A, Zarrin M, Beheshti Fard M. Antifungal Susceptibility of Candida Species Isolated From Candiduria.Jundishapur J Microbiol. 2013;6(1):24-8. DOI: 10.5812/jjm.4633

* Corresponding author: Majid Zarrin, Department of Medical Mycology, School of Medicine, Ahvaz Jundishapur University of Medical Sciences, Ahvaz, IR Iran.

Tel:+98-6113330074. Fax:+98-6113332036, E-mail: mjzarrin@yahoo.co.uk

DOI:10.5812/jjm.4633

(C) 2013 Ahvaz Jundishapur University of Medical Sciences; Published by Kowsar Corp.

This is an Open Access article distributed under the terms of the Creative Commons Attribution License (http://creativecommons.org/licenses/by/3.0), which permits unrestricted use, distribution, and reproduction in any medium, provided the original work is properly cited. 


\section{Background}

Candiduria is one of the most common symptoms of urinary tract infections caused by several species of Candida, which is a normal flora of human body. Candida albicans has played an important role in candiduria $(1,2)$, however during the last decades non-albicans, such as $C$. glabrata, and C. tropicalis, have gradually increased in the incidence of nosocomial infections (1, 3-6). Old age, long stayin hospital, using broad spectrum antibiotics, and renal defects are the most important predisposing factors for candiduria $(1,5,7,8)$. Several reports have indicated that candiduria is a very common infection in hospitalized patients and its incidence is linked to antibiotic usage, long stay in hospitals, old age etc $(2,6,9)$.

There are several valuable antifungals, such as amphotericine B, itraconazole, fluconazole, ketoconazole, econazole and nystatin, that are effective against Candida species. Some of these agents (fluconazole, amphotericine B, ketoconazole, econazole, itraconazole) are systemically used to treat urinary tract infections (UTI) $(4,10)$. Several reports have demonstrated that antifungal fluconazole has been effective for short-term eradication of candiduria $(1,11)$. On the other hand, some researches have found that the susceptibility degree of Candida species vary towards the used antifungal drugs $(6,7)$. For example, C. krusei and C. glabrata are resistant and less susceptible to fluconazole, respectively $(7,8,12)$. Recent reports from different countries and hospitals have indicated that there has been an association between non-albicans and the rate of fluconazole resistance (12-14).

The susceptibility degrees of Candida species towards the used antifungal drugs vary and due to the growing use of these antifungals, resistance to these agents has increased during the last decades (14).

\section{Objectives}

The present study aimed to determine the susceptibilities to antifungal drugs of Candida species isolated from candiduria in hospitalized patients of educational hospitals in Ahvaz.

\section{Materials and Methods}

\subsection{Tested Yeasts and Identification}

In the present study, 92 Candida spp. isolates , and one Geotrichum spp. isolate were used for susceptibility tests. All species had been previously isolated from urine samples of hospitalized patients in the two educational hospitals in Ahvaz and identified by routine methods. Tested Candida isolates were included, C. albicans (58, 62.3\%), C. glabrata (25, 26.8\%), C. tropicalis (4, 4.3\%), C. krusei (1, 1.1\%), and Candida spp. (4, 4.3\%). In addition, one isolate (1.1\%) of Geotrichum spp. was also used for susceptibility tests. All strains were preserved in sterile distilled water at refrigerator temperature. The isolates were first subcultured on CHROMagar Candida (CHROMagar Candida ${ }^{\circledR}$, France) plates and incubated at $37^{\circ} \mathrm{C}$ for $24 \mathrm{~h}$, aerobically to check for purity. All isolates were re-identified based on standard mycological methods, morphology on CHROMagar Candida, morphology on cornmeal agar, germ tube production and growth at $45^{\circ} \mathrm{C}$. Then a suspension of each isolate of overnight cultures was prepared in $1 \mathrm{ml}$ of sterile PBS and adjusted to 0.5 McFarland turbidity standards.

\subsection{Susceptibility Method}

two sterile swabs were dipped into the suspension and rolled separately on the surface of two series of plates containing Sabouraud dextrose agar SDA (Merck, Germany) as lawn (17). The inoculated plates were dried in laminar hood at ambient temperature for 15 mins. Paper disks of antifungals were placed on plates (three antifungal disks for each plate) by forceps and incubated at $37^{\circ} \mathrm{C}$ for $24 \mathrm{~h}$, aerobically. Antifungal disks were nystatin (100U), amphotericine B $(20 \mu \mathrm{g})$, fluconazole $(100 \mu \mathrm{g})$, ketocon-

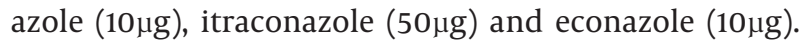
All antifungal disks were purchased from Liofilchem Bacteriology Products (Italy). After 24h, the zone diameter around each antifungal disk was manually measured by ruler and recorded.

\section{Results}

\subsection{Interpretive Criteria for Susceptibility of Antifungals}

The interpretive criteria for the fluconazole, nystatin, amphotericine $\mathrm{B}$, ketoconazole, itraconazole and econazole disks were indicated in Table 1 $(15,16)$.

Table 1. Interpretive Criteria of Susceptibility and Resistance of Used Antifungal Disks

\begin{tabular}{llll|}
\hline & \multicolumn{3}{c}{ Zone Diameter in mm } \\
\cline { 2 - 4 } & Sensitive & Dose Dependent & Resistance \\
\hline Amphotericine B & $>15$ & $10-14$ & $<9$ \\
Nystatin & $\geq 25$ & $17-24$ & $<16$ \\
Fluconazole & $\geq 19$ & $15-18$ & $\leq 14$ \\
Itraconazole & $>16$ & $10-15$ & $<9$ \\
Ketoconazole & $\geq 30$ & $29-23$ & $\leq 22$ \\
Econazole & $>16$ & $10-15$ & $<9$ \\
\hline
\end{tabular}

\subsection{Susceptibility to Amphotericine B}

In the present study $54.8 \%$ and $44.1 \%$ were dose dependent and sensitive to amphotericine $\mathrm{B}$, respectively (Table 2). $44.8 \%$ of C. albicans isolates were dose dependent and the rest of them (55.2) were sensitive to amphotericine B. One isolate (4\%) of C. glabrata was resistant to amphotericine $\mathrm{B}$, whereas 15 (60\%) and 9 (36\%) were dose dependent and sensitive to amphotericine $\mathrm{B}$, respectively.

\subsection{Susceptibility to Itraconazole}

Susceptibility of tested isolates indicated that only one iso- 


\begin{tabular}{|c|c|c|c|c|c|c|c|}
\hline Amphotericine B & C. albicans & C. glabrata & Candida sp. & C. tropicalis & C. krusei & Geotrichum & Total \\
\hline Resistance & $0(0.0 \%)$ & $1(1.1 \%)$ & $0(0.0 \%)$ & $0(0.0 \%)$ & $0(0.0 \%)$ & $0(0.0 \%)$ & $1(1.1 \%)$ \\
\hline Dose dependent & $26(28.0 \%)$ & $15(16.1 \%)$ & $4(4.3 \%)$ & $4(4.3 \%)$ & $1(1.1 \%)$ & $1(1.1 \%)$ & $51(54.8 \%)$ \\
\hline Sensitive & $32(34.4 \%)$ & $9(9.7 \%)$ & $0(0.0 \%)$ & $0(0.0 \%)$ & $0(0.0 \%)$ & $0(0.0 \%)$ & $41(44.1 \%)$ \\
\hline Total & $58(62.4 \%)$ & $25(26.9 \%)$ & $4(4.3 \%)$ & $4(4.3 \%)$ & $1(1.1 \%)$ & $1(1.1 \%)$ & $93(100 \%)$ \\
\hline \multicolumn{8}{|l|}{ Itraconazole } \\
\hline Resistance & $0(0.0 \%)$ & $0(0.0 \%)$ & $0(0.0 \%)$ & $0(0.0 \%)$ & $1(1.1 \%)$ & $0(0.0 \%)$ & $1(1.1 \%)$ \\
\hline Dose dependent & $52(55.9 \%)$ & $24(25.8 \%)$ & $4(4.3 \%)$ & $4(4.3 \%)$ & $0(0.0 \%)$ & $1(1.1 \%)$ & $85(91.4 \%)$ \\
\hline Sensitive & $6(6.5 \%)$ & $1(1.1 \%)$ & $0(0.0 \%)$ & $0(0.0 \%)$ & $0(0.0 \%)$ & $0(0.0 \%)$ & $7(7.5 \%)$ \\
\hline Total & $58(62.4 \%)$ & $25(26.9 \%)$ & $4(4.3 \%)$ & $4(4.3 \%)$ & $1(1.1 \%)$ & $1(1.1 \%)$ & $93(100 \%)$ \\
\hline \multicolumn{8}{|l|}{ Nystatin } \\
\hline Resistance & $0(0.0 \%)$ & $1(1.1 \%)$ & $0(0.0 \%)$ & $0(0.0 \%)$ & $0(0.0 \%)$ & $0(0.0 \%)$ & $1(1.1 \%)$ \\
\hline Dose dependent & $23(24.7 \%)$ & $20(21.5 \%)$ & $4(4.3 \%)$ & $2(2.2 \%)$ & $1(1.1 \%)$ & $1(1.1 \%)$ & $51(54.8 \%)$ \\
\hline Sensitive & $35(37.6 \%)$ & $4(4.3 \%)$ & $0(0.0 \%)$ & $2(2.2 \%)$ & $0(0.0 \%)$ & $0(0.0 \%)$ & $41(44.1 \%)$ \\
\hline Total & $58(62.4 \%)$ & $25(26.9 \%)$ & $4(4.3 \%)$ & $4(4.3 \%)$ & $1(1.1 \%)$ & $1(1.1 \%)$ & $93(100 \%)$ \\
\hline \multicolumn{8}{|l|}{ Econazole } \\
\hline Resistance & $0(0.0 \%)$ & $0(0.0 \%)$ & $0(0.0 \%)$ & $0(0.0 \%)$ & $0(0.0 \%)$ & $0(0.0 \%)$ & $0(0.0 \%)$ \\
\hline Dose dependent & $4(4.3 \%)$ & $2(2.2 \%)$ & $0(0.0 \%)$ & $0(0.0 \%)$ & $0(0.0 \%)$ & $0(0.0 \%)$ & $6(6.5 \%)$ \\
\hline Sensitive & $54(58.1 \%)$ & $23(24.7 \%)$ & $4(4.3 \%)$ & $4(4.3 \%)$ & $1(1.1 \%)$ & $1(1.1 \%)$ & $33(93.5 \%)$ \\
\hline Total & $58(62.4 \%)$ & $25(26.9 \%)$ & $4(4.3 \%)$ & $4(4.3 \%)$ & $1(1.1 \%)$ & $1(1.1 \%)$ & $93(100 \%)$ \\
\hline \multicolumn{8}{|l|}{ Fluconazole } \\
\hline Resistance & $32(34.4 \%)$ & $7(7.5 \%)$ & $2(2.2 \%)$ & $2(2.2 \%)$ & $1(1.1 \%)$ & $1(1.1 \%)$ & $45(48.4 \%)$ \\
\hline Dose dependent & $17(18.3 \%)$ & $16(17.2 \%)$ & $1(1.1 \%)$ & $2(2.2 \%)$ & $0(0.0 \%)$ & $0(0.0 \%)$ & $36(38.7 \%)$ \\
\hline Sensitive & $9(9.7 \%)$ & $2(2.2 \%)$ & $1(1.1 \%)$ & $0(0.0 \%)$ & $0(0.0 \%)$ & $0(0.0 \%)$ & $12(12.9 \%)$ \\
\hline Total & $58(62.4 \%)$ & $25(26.9 \%)$ & $4(4.3 \%)$ & $4(4.3 \%)$ & $1(1.1 \%)$ & $1(1.1 \%)$ & $93(100 \%)$ \\
\hline \multicolumn{8}{|l|}{ Ketoconazole } \\
\hline Resistance & $19(20.4 \%)$ & $4(4.3 \%)$ & $2(2.2 \%)$ & $0(0.0 \%)$ & $0(0.0 \%)$ & $0(0.0 \%)$ & $25(26.9 \%)$ \\
\hline Dose dependent & $31(33.3 \%)$ & $14(15.1 \%)$ & $0(0.0 \%)$ & $4(4.3 \%)$ & $1(1.1 \%)$ & $0(0.0 \%)$ & $50(53.8 \%)$ \\
\hline Sensitive & $8(8.6 \%)$ & $7(7.5 \%)$ & $2(2.2 \%)$ & $0(0.0 \%)$ & $0(0.0 \%)$ & $1(1.1 \%)$ & $18(19.4 \%)$ \\
\hline Total & $58(62.4 \%)$ & $25(26.9 \%)$ & $4(4.3 \%)$ & $4(4.3 \%)$ & $1(1.1 \%)$ & $1(1.1 \%)$ & $93(100 \%)$ \\
\hline
\end{tabular}

late of C. krusei was resistant to itraconazole. $91.4 \%$ of isolates were dose dependent and $7.5 \%$ were sensitive to itraconazole (Table 2). Overall, it was evident that $89.7 \%$ and $96.0 \%$ of C. albicans and C. glabrata were respectively exhibited dose dependent and the rest of them were sensitive.

\subsection{Susceptibility to Nystatin}

The details of susceptibility tested isolates to nystatin were shown in Table 2. As indicated, $54.8 \%$ and $44.1 \%$ of tested isolates were dose dependent and sensitive to nystatin, respectively. In the present study, only one isolate (1.1\%) of C. glabrata was resistant to nystatin. Totally $39.7 \%$ and $80.0 \%$ of C. albicans and C. glabrata were dose dependent to nystatin, respectively, whereas $60.3 \%$ and $16.0 \%$ of C. albicans and C. glabrata were sensitive to nystatin, respectively.

\subsection{Susceptibility to Econazole}

The results of susceptibilities to econazole indicated that most of the tested isolates (93.5\%) were sensitive to econazole and the rest of them were dose dependent ( $\mathrm{Ta}$ ble 2). Besides, $93.1 \%$ and $92.0 \%$ isolates of $C$. albicans and $C$. glabrata were sensitive to econazole and the rest of them were dose dependent.

\subsection{Susceptibility to Fluconazole}

Table 2 shows the susceptibility details of 93 tested isolates to fluconazole. As indicated, the zones around $48.4 \%$ of isolates were resistant to fluconazole, $38.7 \%$ dose dependent and $12.9 \%$ sensitive. When looking into C. albicans, 32 (55.2\%) of isolates were resistant to fluconazole followed by, 17 (29.3\%) dose dependent and 9 (15.5\%) sensitive. Also, results indicated that 7 (28.0\%) of C. glabrata were resistant to drug, followed by 16 (64.0\%) dose dependent and 2 (8.0\%) sensitive.

\subsection{Susceptibility to ketoconazole}

The susceptibility details of tested isolates to ketoconazole were shown in Table 2. As shown 26.9\%, 53.8\% and $19.4 \%$ of isolates were respectively resistant, dose depen- 
dent and sensitive to ketoconazole. Totally 53.4\% and 56\% of C. albicans and C. glabrata were dose dependent to ketoconazole, respectively. In the present study $32.8 \%$ and $13.8 \%$ of C. albicans were respectively resistant and sensitive to ketoconazole compared to $16.0 \%$ and $28.8 \%$ of $C$. glabrata.

\section{Discussion}

Fungal UTI has become an important nosocomial infection over the past decades among hospitalized patients. In addition, the extensive use of antifungals in hospitals may be a risk of emergence of resistant fungal strains (17, 18). For example, fluconazole is an important antifungal drug that is usually used to treat systemic fungal infections caused by Candida species. In addition, prophylaxis against systemic fungal diseases is also more prevalent by fluconazole.

The susceptibility of Candida species to frequently used antifungal drugs has various degrees. It has been reported that non-albicans species, C. glabrata, C. tropicalis, C. krusei, C. parapsilosis and C. lusitaniae have had higher resistance rates against fluconazole than C. albicans (19).

C. krusei is one of the rare isolates of candiduria that is basically resistant to fluconazole (20), however several reports have different results. It is important to note that in the present study C. krusei was dose dependent to amphotericine $\mathrm{B}$, nystatin, and ketoconazole and sensitive to econazole. In addition, this isolate was quite resistant to both itraconazole and fluconazole antifungal drugs. Ozcelik et al. (18) have reported that this isolate is quite sensitive to amphotericine B, in contrast, Pfaller et al. (16) showed that C. krusei is resistant to amphotericine B. In addition, Cheng et al. (13) showed that several strains of C. krusei isolated from candidemia were resistant to amphotericine B. In a study conducted by Yang et al. (14) 70\% of C. krusei isolates, collected from different hospitals of several regions of Taiwan, were resistant to fluconazole. They concluded that different resistance rates to fluconazole associated with different conditions in hospitals of each region.

The resistance rate of $C$. glabrata to fluconazole has gradually increased during last decades (19). ManzanoGayosso et al. (4) study revealed that itraconazole, amphotericine $\mathrm{B}$, and ketoconazole had less antifungal activity against $C$. glabrata isolates. In a study conducted by Laverdiere et al. (17), $4 \%$ of the Candida species isolated from different parts of ICUs patients were resistant to fluconazole and/or itraconazole. They believed that extensive use of antifungals in hospitals may be a risk of emergence of resistant fungal strains.

It is suggested by the current study that controlled surveys must be undertaken to optimize antifungal therapy based on characteristics of Candida strains. The current study indicated that $7.5 \%$ of C. glabrata isolates were resistant to fluconazole. It should be considered when $C$. glabrata is commonly isolated, fluconazole is a frequent choice for treatment and prevention of fungal diseases. The highest fluconazole sensitivity rates were recognized among C. albicans with 9.7\%, while none of the isolates of C. tropicalis, C. krusei and Geotrichum spp. were susceptible.

There was no econazole resistance identified in the current study, and higher econazole sensitivity was found in C. albicans in $58.1 \%$ of isolates. This result strongly indicates that econazole is very effective against $C$. albicans. It is concluded that Candida species isolated from candiduria in hospitalized patients have excellent in vitro activities against econazole. Other suitable antifungal drugs were itraconazole, nystatin and amphotericine. Whereas, resistance against ketoconazole (26.9\%) and especially fluconazole (48.4\%) was significant.

\section{Acknowledgments}

This work was supported with grant by the Ahvaz Jundishapur University of Medical Sciences, Iran (No. U88047). In addition this article has been extracted from an MD thesis (Maryam Beheshti Fard).

\section{Financial Disclosure}

The authors state no conflict of interest.

\section{Funding/Support}

None declared.

\section{Authors' Contribution}

None declared.

\section{References}

1. Bukhary ZA. Candiduria: a review of clinical significance and management. Saudi J Kidney Dis Transpl. 2008;19(3):350-60.

2. Nayman Alpat S, Ozgunes I, Ertem OT, Erben N, Doyuk Kartal E, Tozun M, et al. [Evaluation of risk factors in patients with candiduria]. Mikrobiyol Bul. 2011;45(2):318-24.

3. Kobayashi CC, de Fernandes OF, Miranda KC, de Sousa ED, Silva Mdo R. Candiduria in hospital patients: a study prospective. $M y$ copathologia. 2004;158(1):49-52.

4. Manzano-Gayosso P, Hernandez-Hernandez F, Zavala-Velasquez N, Mendez-Tovar LJ, Naquid-Narvaez JM, Torres-Rodriguez JM, et al. [Candiduria in type 2 diabetes mellitus patients and its clinical significance. Candida spp. antifungal susceptibility]. Rev Med Inst Mex Seguro Soc. 2008;46(6):603-10.

5. Sellami A, Sellami H, Makni F, Bahloul M, Cheikh-Rouhou F, Bouaziz M, et al. [Candiduria in intensive care unit: significance and value of yeast numeration in urine]. Ann Fr Anesth Reanim. 2006;25(6):584-8.

6. Weinberger M, Sweet S, Leibovici L, Pitlik SD, Samra Z. Correlation between candiduria and departmental antibiotic use. J Hosp Infect. 2003;53(3):183-6.

7. Achkar JM, Fries BC. Candida infections of the genitourinary tract. Clin Microbiol Rev. 2010;23(2):253-73.

8. Nucci M. Candiduria in hospitalized patients: a review. Braz J Infect Dis. 2000;4(4):168-72.

9. Dalen DM, Zvonar RK, Jessamine PG. An evaluation of the management of asymptomatic catheter-associated bacteriuria and 
candiduria at The Ottawa Hospital. Can J Infect Dis Med Microbiol. 2005;16(3):166-70.

10. Carvalho M, Guimaraes CM, Mayer JR, Jr., Bordignon GP, QueirozTelles F. Hospital-associated funguria: analysis of risk factors, clinical presentation and outcome. Braz Infect Dis. 2001;5(6):313-8.

11. Fisher JF, Sobel JD, Kauffman CA, Newman CA. Candida urinary tract infections-treatment. Clin Infect Dis. 2011;52 Suppl 6:S45766.

12. Yang YL, Cheng MF, Chang YW, Young TG, Chi H, Lee SC, et al. Host factors do not influence the colonization or infection by fluconazole resistant Candida species in hospitalized patients. J Negat Results Biomed. 2008;7:12.

13. Cheng MF, Yu KW, Tang RB, Fan YH, Yang YL, Hsieh KS, et al. Distribution and antifungal susceptibility of Candida species causing candidemia from 1996 to 1999. Diagn Microbiol Infect Dis. 2004;48(1):33-7.

14. Yang YL, Cheng HH, Ho YA, Hsiao CF, Lo HJ. Fluconazole resistance rate of Candida species from different regions and hospital types in Taiwan. J Microbiol Immunol Infect. 2003;36(3):187-91.

15. Pakshir K, Bahaedinie L, Rezaei Z, Sodaifi M, Zomorodian K. In vitro activity of six antifungal drugs against clinically important dermatophytes. JundishapurJMicrobiol. 2011;2(4):158-63.
16. Pfaller MA, Diekema DJ, Colombo AL, Kibbler C, Ng KP, Gibbs DL, et al. Candida rugosa, an emerging fungal pathogen with resistance to azoles: geographic and temporal trends from the artemis disk antifungal surveillance program. J Clin Microbiol. 2006;44(10):3578-82.

17. Laverdiere M, Labbe AC, Restieri C, Rotstein C, Heyland D, Madger $S$, et al. Susceptibility patterns of Candida species recovered from Canadian intensive care units. J Crit Care. 2007;22(3):245-50.

18. Ozcelik B, Kaynak F, Cesur S, Sipahi B, Sultan N. In vitro activities of voriconazole as a triazole derivative and caspofungin as an echinocandin were compared with those of some antifungal agents against Candida species isolated from clinical specimens. Jpn J Infect Dis. 2007;60(5):302-4.

19. Al-Abeid HM, Abu-Elteen KH, Elkarmi AZ, Hamad MA. Isolation and characterization of Candida spp. in Jordanian cancer patients: prevalence, pathogenic determinants, and antifungal sensitivity.Jpn J Infect Dis. 2004;57(6):279-84.

20. Quindos G, Abarca L, Carrillo-Munoz AJ, Arevalo MP, Bornay FJ, Casals JB, et al. Multicenter survey of in vitro antifungal resistance in yeasts of medical importance isolated from Spanish patients. Rev Iberoam Micol. 1999;16(2):97-100. 